\title{
Student-led outreach and public engagement activities at the University of Southampton to celebrate the inaugural International Day of Light
}

Callum Stirling, Andrei Donko, Neda Baktash, Katarzyna Grabska, Angeles Camacho Rosales, et al.

Callum J. Stirling, Andrei L. Donko, Neda Baktash, Katarzyna Grabska, Angeles L. Camacho Rosales, Dean T. Clarke, Jake J. Prentice, Matthew T. Posner, "Student-led outreach and public engagement activities at the University of Southampton to celebrate the inaugural International Day of Light," Proc. SPIE 10741, Optics Education and Outreach V, 107410B (14 September 2018); doi: 10.1117/12.2320304

SPIE Event: SPIE Optical Engineering + Applications, 2018, San Diego, California, United States 


\title{
Student-led outreach and public engagement activities at the University of Southampton to celebrate the inaugural International Day of Light
}

\author{
Callum J. Stirling*a, Andrei L. Donko ${ }^{\mathrm{a}}$, Neda Baktash ${ }^{\mathrm{a}}$, Katarzyna Grabska ${ }^{\mathrm{a}}$, Angeles L. Camacho \\ Rosales $^{\mathrm{a}}$, Dean T. Clarke ${ }^{\mathrm{a}}$, Jake J. Prentice ${ }^{\mathrm{a}}$, Matthew T. Posner ${ }^{\mathrm{a}}$ \\ ${ }^{a}$ Optoelectronics Research Centre, University of Southampton, University Road, Southampton, \\ SO17 1BJ, United Kingdom
}

\begin{abstract}
The $16^{\text {th }}$ May 2018 marks the first annual International Day of Light (IDL). The steering committee of the IDL initiative encouraged grassroots activities to increase the awareness and understanding of the applications of light. One such undertaking is the program of events developed by the postgraduate students of the Optoelectronics Research Centre (ORC) at the University of Southampton (UoS). The program focused on engaging with the public and local schools with low levels of progression to higher education. Three events were designed: an outreach masterclass, combining activities and demonstrations from well-established workshops covering light in telecommunications, manufacturing and medicine; an art competition in a local school, for students to express scientific knowledge in a creative way; and a public panel, to explore the uses of light in a multitude of disciplines and open academic research to a broader audience. This paper explains how the events built on the ORC students' long history of outreach and the legacy of the International Year of Light. Each event is outlined in detail, explaining the objectives and the rationale behind the audience selection. The program outcomes are described, including the impact, the methods employed and the utilization of expert partners to increase the program reach (commercial media, local schools and UoS's diversity and inclusion outreach department), and the lessons learned from the program are assessed. These experiences can be used to recycle and adapt this format for other grassroots IDL programs. This project received funding through a SPIE IDL Micro Grant.
\end{abstract}

Keywords: International Day of Light, outreach education, public engagement, photonics, STEM, STEAM, widening participation, diversity and inclusion

\section{INTRODUCTION}

On $7^{\text {th }}$ November 2017, the United Nationals Educational, Scientific and Culture Organization (UNESCO) at their General Conference proclaimed the date of $16^{\text {th }}$ May as the International Day of Light (IDL) ${ }^{1}$. This initiative was designed to pursue the mission of raising global awareness about how light-based technologies promote sustainable development and can provide solutions to the global challenges in energy, education, agriculture, and health initiated during the 2015 International Year of Light ${ }^{2}$. The postgraduate students at the Optoelectronics Research Centre (ORC) at the University of Southampton (UoS) developed a program of grassroots events to celebrate the IDL 2018, as was encouraged by the steering committee of the IDL. The format of these events presented could be recycled and adapted by other groups wishing to celebrate the IDL in the future.

The content of this paper is as follows. Section 2 details the history of outreach and public engagement by students at the ORC. The longstanding outreach program, the Lightwave Roadshow, and the legacy of the IYL 2015 were the foundations for the activities for the IDL 2018. Section 3 introduces the design of the program and how it aligns with the objectives of the IDL. In section 4, the focus is on the practicalities of delivering the program, explaining the audience selection rationale and a summary of what was achieved. Finally, section 5 discusses how this program can be adapted to a reusable format for future IDL activities, as well as advising future groups on how to maximize their resources using this format.

$$
\text { *c.stirling@soton.ac.uk; +44 (0)23 } 8059 \text { 2697; www.orc.soton.ac.uk }
$$




\section{BACKGROUND}

\subsection{Context for Outreach and Public Engagement in the UK}

Since the limit of tuitions fees for degree courses in the UK was increased in 2012, universities have had obligations under access and participation plans for underrepresented groups in higher education if they wish to charge higher fees ${ }^{3}$. Moreover, the research councils in the UK, that determine the distribution of public funding for research, are signatories of the Concordat for Engaging the Public with Research for public engagement to be embedded directly alongside research ${ }^{4}$. Consequently, researchers at UoS, including the postgraduate research (PGR) students, are working in an environment in which there is a great focus on creating science education and public engagement programs that are based around research, particularly those that engage audiences from disadvantaged backgrounds or that do not traditionally engage with higher education.

\subsection{The Optics and Photonics Society}

The Optics and Photonics Society (OPSoc) is the postgraduate student society at the UoS for research students working in these fields, with strong representation from the ORC. It combines the UoS student chapters of International Society for Optics and Photonics (SPIE), The Optical Society (OSA) and the IEEE Photonics Society (IPS). These three organizations form part of the steering committee for the IDL, so working through their UoS student chapters allows cooperation with the international celebration and access to grants for the IDL 2018.

The aim of OPSoc is to provide an environment for students to communicate their research expand and enhance their professional development, as well as encourage social activities to working relationships between students ${ }^{3}$. As a student chapter, OPSoc also organizes visits to industry and other scientific and technological sites, invites speakers and organizes conferences. ${ }^{4}$. The Outreach and Diversity offices also work with groups that have low representation in Science, Technology, Engineering and Mathematics (STEM), to encourage them to study these subjects at a higher level or to pursue them as a career.

\subsection{The Lightwave Roadshow}

The Lightwave Roadshow (often referred to as just Lightwave) is a PGR student-led optics and photonics outreach program with many activities designed to engage young students and the wider public. The aims of the program are simple: to educate, to inform, and to inspire. Lightwave was created by the UoS OSA Student Chapter (later to become OPSoc) in 1998 and is directed by its Outreach Officers. Further details on the origins of the program and the role of the Outreach Officers can be found in earlier literature 5 . The reader is also referred to a previous paper that details the workshop format offered by Lightwave ${ }^{6}$.

Over the past two decades, Lightwave has continuously expanded its range of activities from its initial focus on primary schools (5 - 11 years old), youth clubs and science fairs to include the wider general public and older pupils in secondary school (11 - 16 years old) and college (16 - 18 years old). This expansion was achieved through close partnerships with schools and other UoS outreach programs. As Lightwave's reputation increases among schools, so too does the demand for activities. To help meet the demand, the most well-established Lightwave workshops have been formalized with lesson plans to reinforce and enhance the UK National Curriculum (some can be found in Posner's doctoral thesis ${ }^{7}$ ).

The program has continued to enjoy success and interaction with a large audience; in 2017 alone, Lightwave has engaged with over 2000 people. This was achieved through school visits, fairs, bringing schoolchildren onto the UoS campus and high impact events focusing on target STEM demographics (such as girls and children from lower socioeconomic backgrounds). The heritage and success of the Lightwave Roadshow enabled the creation of new partnerships, as well as the collaboration with existing ones, for the IDL 2018. Furthermore, the experience gained by the Outreach Officers in running Lightwave facilitated the delivery of the IDL 2018 program.

\subsection{The International Year of Light 2015 at the University of Southampton}

To capitalize on the IYL 2015, several initiatives were implemented at the UoS, such as the development of a portable kit to reach international audiences ${ }^{7}$. Multidisciplinary activities were found to be particularly effective at engaging with non-traditional audiences; the incorporation of art into science outreach, through the presentation of optical fiber optics research at the Royal Horticultural Show garden show ${ }^{8}$, attracted new audiences with a lot of positive behavior and changes in attitude towards science and technology. Another focus was developing school-university partnerships during the IYL 2015, which led to students (both from schools and UoS) attending the IYL 2015 opening ceremony at the 
UNESCO headquarters in Paris ${ }^{9}$. This further emphasized the interdisciplinary nature of the work around light, as the students experienced the impact of individuals from very different backgrounds working together. The activities fed back into the Lightwave Roadshow and there has been significant effort to combine science, education, and culture in the core activities of the program.

\section{PROGRAM OUTLINE}

\subsection{Goals for the University of Southampton celebrations}

Based on the goals set out for the IDL $^{10}$, three main themes were chosen for this outreach and public engagement project: increasing the awareness of how light and its applications are present in everyday life; using light-based activities to develop STEM education; and highlighting the uses of light in a multitude of disciplines, particularly the links between light and art. These were also the themes that had been previously used successfully by OPSoc, the Lightwave Roadshow and in the IYL 2015. This meant that the experience developed in these activities directly contributed to the design of the IDL program and allowed the authors to explore a range of events that put postgraduate researchers, school pupils and members of the public at the center of the program. Three events, described in the following sections, were devised around these themes: a public forum, an outreach masterclass, and an art competition.

\subsection{Public Forum}

The public forum was an event to showcase the varied applications of light, covering fundamental and applied research industry and engineering, medicine, and the arts. A panel of expert speakers delivered a series of short talks on the use of light in their fields, with opportunity for discussion at the end of the talks. This multidisciplinary event was open to the public, with invited representatives from academia, industry, local schools (teachers, pupils, and parents) and artists. A buffet reception followed the talks, not only to facilitate networking between academics of different disciplines and industry members, but more importantly to allow members of the public to be meet academics in a normalizing way and to hopefully break stereotypes around scientists studying STEM at a high level. To further increase the accessibility of research, a poster competition for PGR students to articulate their work in a manner comprehensible to the general public was also planned. The entries could be from any discipline, provided that the work detailed used light in some way.

\subsection{Outreach Masterclass}

The outreach masterclass was designed to illustrate the applications of light for adolescents (specifically, $14-15$ years old). The masterclass was planned as a day-long event broken into four separate parts: three individual workshops followed by a professional and award-winning laser light show, Light Express ${ }^{11}$. The workshops ("Mobile Ghosts", "Hour in the Life of a Light Scientist" and "Guess the Gas") were chosen from pre-existing classes that had previously been run through the Lightwave Roadshow or associated outreach programs. These aimed to capture the pupils' imagination and cover the basic physical concepts underpinning the demonstrated technology, such as total internal reflection and spectroscopy. By holding the event on the UoS campus and using full-time PGR students to run the workshops, the pupils would also be exposed to the potential careers that exist in the field.

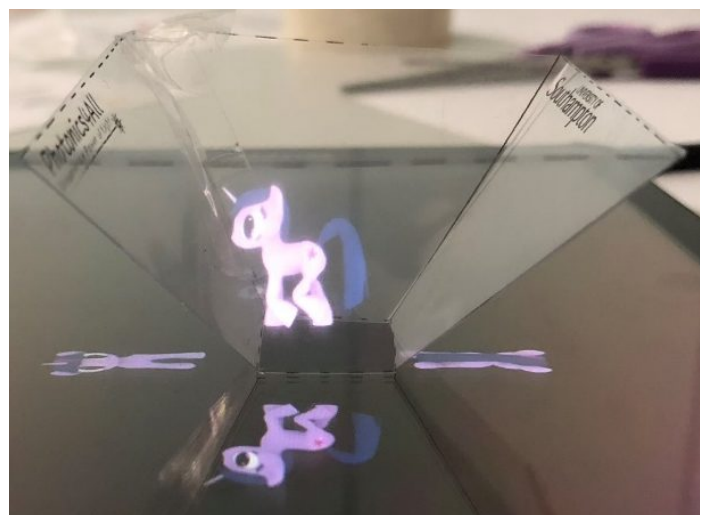

Figure 1: Demonstration of the "Mobile Ghosts" activity using a tablet. The pyramidal 3D projector is made from a net printed on a sheet of acetate, so they are cheap to reproduce and students can take them away after the workshop. 
"Mobile Ghosts" is based on a demonstration more commonly known as "Pepper's Ghost". It is predominately a practical workshop where students build their own three-dimensional (3D) projector using a smart phone or tablet (see Figure 1). The session begins with the workshop coordinators introducing themselves and briefly describing photonics, first in general and then their own research. After this, they discuss with the pupils how reflection and transmission are applied to the "ghost" phenomenon and how this can be used to explain how our eyes perceive objects in three dimensions. The demonstrators also emphasise the difference between this and a true hologram. The practical element involves assembling their own projectors and testing them using a smart phone or tablet and videos that can be widely found on YouTube.

The "Hour in the Life of a Light Scientist" workshop was designed to give students a glimpse into life as a researcher working with light, to broaden students' knowledge of potential careers within STEM. The session was divided into two sections: an introductory lecture followed by a team problem-solving activity. The lecture describes various applications of light such as in medicine or manufacturing (drawing from the demonstrator's own work), but in particular discusses the underpinning of the Internet by optical fibers. To show how information is sent using light, a telecommunications demonstration in which a video is transmitted with a red laser in free space was used. This was followed by a discussion on why free-space lasers are not used in practice, leading to the conclusion on the importance of using optical fibers. As an explanation for how optical fibers work, the concept of total internal reflection was illustrated through the Tyndall experiment, in which a laser beam is coupled into a falling water stream and the path of the light beam changes direction. The demonstrations are key to gaining the attention of the audience, but also provide an opportunity for pupil involvement and encourage active participation. The lecture concluded with an explanation of physics behind the operation of a laser. The team activity tested participants on a range of mathematical, linguistic, and practical skills, as well as the assimilation of the knowledge of the laser explanation. The quizzes and practical challenges contain too much for any one pupil to complete by themselves. This intentional overload is designed to encourage teamwork and to prevent extroverted individuals dominating the team, which can often be the case in group activities.

"Guess the Gas" introduces students to the concept of spectroscopy. The workshop began by exploring the basic physical principles of refraction and diffraction, before explaining how they can be used in spectroscopy. The topic was presented in the context of astronomy and its importance when deducing the composition of distant objects in space. To aid their understanding and enhance their retention of the content, pupils then proceed to build their own spectroscope using a paper tube (provided from a template) and a CD. Once built, students tested the spectroscope to identify unknown gases placed in backlit containers around the classroom.

\subsection{Art Competition and IDL Video}

In the last few years, there has been growing interest in the inclusion of the arts and design into the promotion of STEM subjects. The extended Science, Technology, Engineering, Art and Mathematics (STEAM) agenda would increase the creativity of students and provide real-world context for learning ${ }^{12}$. The increasing popularization of STEAM has led to a variety of approaches ${ }^{13}$, including the aforementioned presentation of optical fiber research at a garden show. For the IDL 2018, an art competition in a local school was proposed as a way to push the STEAM agenda, by encouraging schoolchildren to undertake an independent and creative piece of work with light as the focus. Prospective entrants were invited to research topics related to light, such as optical fibers for the internet, photosynthesis, or light phenomena in nature (such as rainbows), and to use this to produce artwork on "How light is important in my everyday life", accompanied by a short description explaining the inspiration of the work. This description (presented to pupils as a "tweet" to encourage brevity) was a means for the pupils to demonstrate their scientific knowledge and understanding. To not limit the creativity of the children, there were no restrictions on the artwork other than that it should fit on a piece of A4 or A3 paper and that it would be mounted vertically, so anything attached should not fall off. Consequently, paintings, drawings, photography, and collage were all acceptable forms of entry. In addition to promoting STEAM, it was hoped that, by using a non-traditional form of science outreach, participation from students who normally shun STEM activities would be increased. To allow for group entries, a maximum of three pupils were chosen as winners, potentially made up from separate entries, a group, or a combination of a pair and an individual.

As an extension of this event and to provide a prize for the art competition, the winning pupils were invited to appear in an online video explaining the IDL to even younger children. In addition to further raising awareness of the IDL, this would provide the opportunity for pupils to grow in confidence and self-pride. It was also proposed that using older children to present the IDL would mean that their descriptions would be more comprehensible to younger children than if PGR students did, because it would have to be understandable to both groups to be effectively communicated. 


\section{DELIVERY}

\subsection{Project Partners}

As with the IYL 2015, collaboration with groups internal and external to the UoS was crucial for the success of this project. Multiple partnerships were formed to maximize the resources available within the limited project budget.

Within the UoS, the Doctoral College provides training and professional training for PGR students and promotes their work. The centerpiece of the advocation of PGR student research is the Festival of Doctoral Research. The authors worked with the Doctoral College so that the public forum was run as part of the Festival, which enabled greater advertisement of the forum by taking advantage of the pre-existing communication channels.

The Access to Southampton (A2S) initiative is the widening participation scheme of the UoS. Its remit is working with local schools local where the uptake of higher education is significantly lower than the national average. Consequently, A2S has a network of 40 secondary schools across the south of England with pupils from target demographics. Involving $\mathrm{A} 2 \mathrm{~S}$ in this project greatly simplified the logistics of the outreach masterclass since they handled all communication with the schools. Furthermore, utilizing the established relationships between the UoS and the schools helped guarantee the uptake in participation of the event; working directly with schools can often be difficult given the time constraints that teachers face.

Cooperation with the Media Development team of Digital Learning at the UoS enabled the filming of the video using professional-standard media equipment without the significant expense of hiring it.

The primary partnership created outside of the UoS was with Cantell School in Southampton, UK. Cantell School is a mixed comprehensive school for ages 11 - 16, that was rated "Good" by the UK Government's Office for Standards in Education, Children's Services and Skills (Ofsted) ${ }^{14}$. Cantell also fulfils the criteria used by A2S and is one of the A2S partner schools. Furthermore, due to some other schools in Southampton being single-sex, the ratio of male to female pupils is roughly 2:1. For this reason, coupled with high educational standards but with low numbers progressing to higher education, the school provided an excellent opportunity for a non-traditional outreach project to have a great impact, particularly in encouraging female pupils in a male-dominated environment. Working directly with teachers at the school (from both the Art and Science departments) who were passionate about this event meant that the art competition could be advertised in ways that would not usually be accessible, such as in school assemblies and Science class. Most effectively, the cooperation of the Science teacher meant that topics in the curriculum related to light were taught ahead of the competition, so all the pupils in the appropriate years had background knowledge of the basic scientific principles of light at the launch of the competition.

Fun Kids is a UK digital radio station with a target audience of $6-11$ years old. In addition to the radio programming, Fun Kids has a large online presence, with a website that hosts videos, podcasts and games and receives tens of thousands of hits each week. Fun Kids agreed to host the IDL video with an accompanying editorial and promote it on their website, in return for acknowledgment of their support and inclusion of their brand in our activities. This included using the Fun Kids logo on the t-shirts that were worn by the demonstrators in the outreach masterclass and on the promotional materials for the events. The use of the Fun Kids website enabled access to larger, age-appropriate audience than could be achieved using the UoS's or OPSoc's online presence and social media channels, maximizing the reach of the video.

\subsection{Public Forum}

Out of the five speakers who contributed to the public forum, four came from the UoS whilst the fifth came from industry. The UoS speakers were chosen from research groups with close connections to industry or photonics-based solutions real-word problems, to demonstrate to the direct public benefit that comes from the use of light-based technologies. The topics covered during the forum were: photonics in telecommunications; interdisciplinary biomedical and chemical imaging; microscale devices for remote environmental sensing in oceans; mapping and chemical analysis of the sea floor using laser-induced plasmas; and the next generation of gas street lighting, fueled by anaerobic digestion of dog excrement and designed to minimize light pollution. Unfortunately, none of the artists approached to speak at the forum were able to attend and an alternative speaker could not be sourced. However, to ensure the representation of art at the forum, the entries from the school art competition were displayed at the buffet reception following the talks. 
The invitations for selected guests were sent out in two phases. Earlier invitations were emails sent to all PGR students at UoS to invite them to both the event and to enter the poster competition, sent out around 6 weeks in advance. To encourage entries, the printing of the first 15 posters was paid for and $£ 50$ Amazon vouchers were offered as a prize. The second group of invitations were emailed 2 weeks after the first to academics at UoS and nearby companies in related industries, particularly to those with connections to the UoS like the ORC spin-outs. The invited audience also served to ensure that there was at least a minimum of attendance at the forum.

To advertise the free event to the public, posters and flyers were distributed in Southampton and the UoS campus, with details posted to the UoS and ORC social media channels. The forum was added to the "Events" section of the International Day of Light website and to the program for the Festival of Doctoral Research. These were all linked back to a webpage (Eventbrite) for the guests to register on, as were the emailed invitations, but registration was not mandatory to attend. This provided a real-time feedback on the number of guests, acting as an indicator if additional advertisement was required and to avoid overspending on the catering for the reception. Furthermore, the online ticketing service would send out reminder emails to guests, which is important for converting registered tickets into attendees, particularly if the event is advertised considerably in advance.

The event was held 5:30pm on the $17^{\text {th }}$ May, the day following the IDL. The scheduling was important, as it was planned to take place outside standard working hours and to allow the audience time to travel to the UoS campus (where the forum was held), but not too late as to discourage people from attending. The forum had to take place on the $17^{\text {th }}$ May to avoid clashes with speaker commitments and with other Festival of Doctoral Research events. In all, 43 tickets out of a maximum of 100 were reserved and $40-50$ people attended (see Figure 2). Approximately two-thirds of the attendees had registered beforehand, so around 10 ticket holders that did not turn up; unfortunately, this is to be expected for an event of this size. Feedback from both the audience and the speakers highlighted the networking aspect of the event positively, although a larger audience would have enhanced this further. To increase this audience in the future, the promotion for the event could be more systematic and planned from the very beginning. Conversely, advertisements and invitations were sent out on a slight $a d$ hoc basis for this event, only $4-6$ weeks ahead of the event.

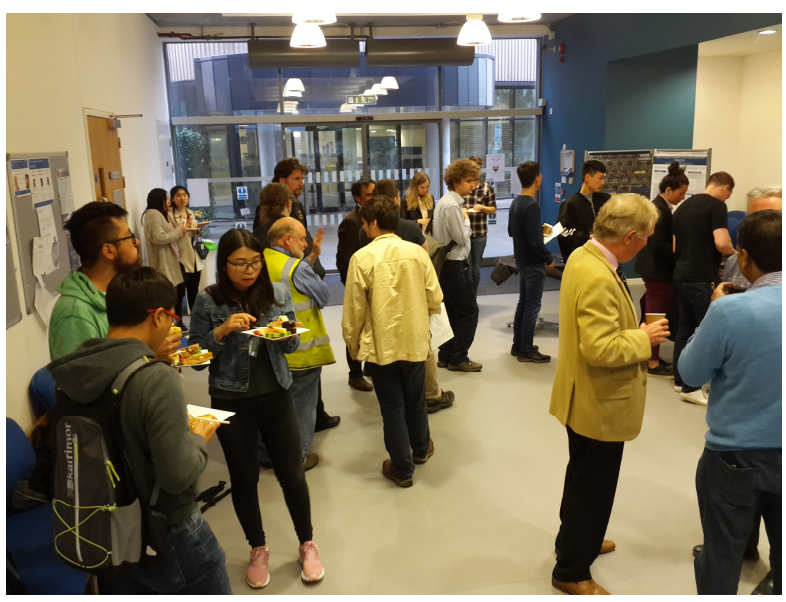

(a)

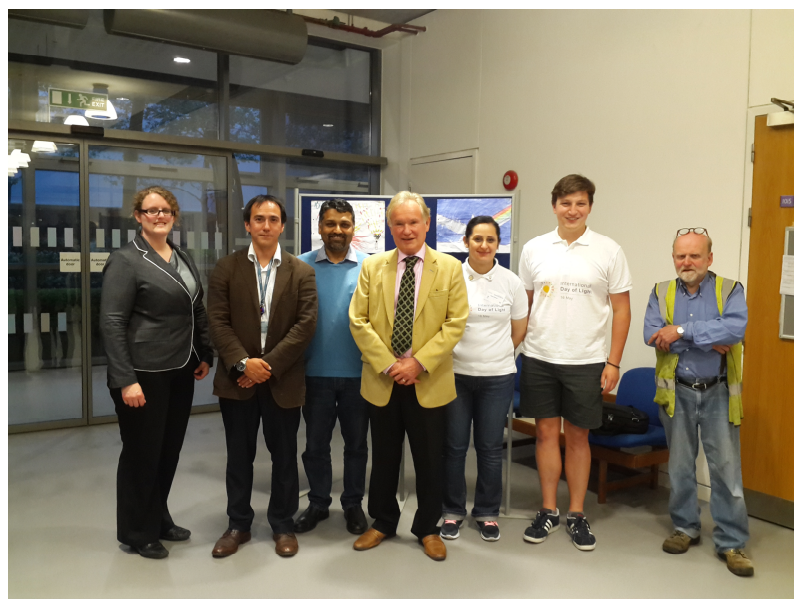

(b)

Figure 2: (a) Guests in attendance at the public forum. (b) The speakers accompanied by Stirling and Baktash.

The poster competition for PGR students only received two entries. The reason behind this is uncertain, but the authors speculate that this was because 6 weeks was not enough time to allow for PGR students to make their poster. An alternative possibility is that the prize offered was insufficient motivation for entries.

\subsection{Outreach Masterclass}

The outreach masterclass was held on the IDL on the UoS campus, to improve the engagement and concentration of the children by removing them from their typical learning environment. A2S contacted their affiliated schools, offering places for up to 15 pupils from each school. From experience with the Lightwave Roadshow, financial restrictions on stringent state school budgets can prevent schools from attending outreach events. To avoid this, A2S also arranged for coach travel between the schools and the UoS campus. The schools were asked to select pupils who were identified as "gifted and talented", to ensure the activity reached those who would benefit most from it. Within 24 hours, 6 schools 
had signed up to the event, filled all 90 places. Unfortunately, one school withdrew at a late stage due to a lack of available staff. As such, 75 pupils attended the event.

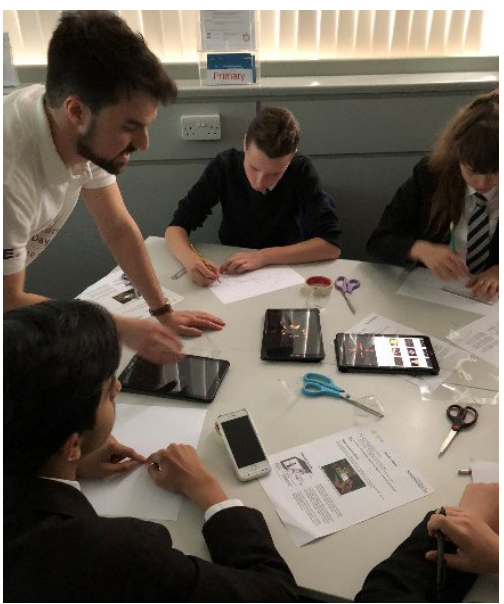

(a)

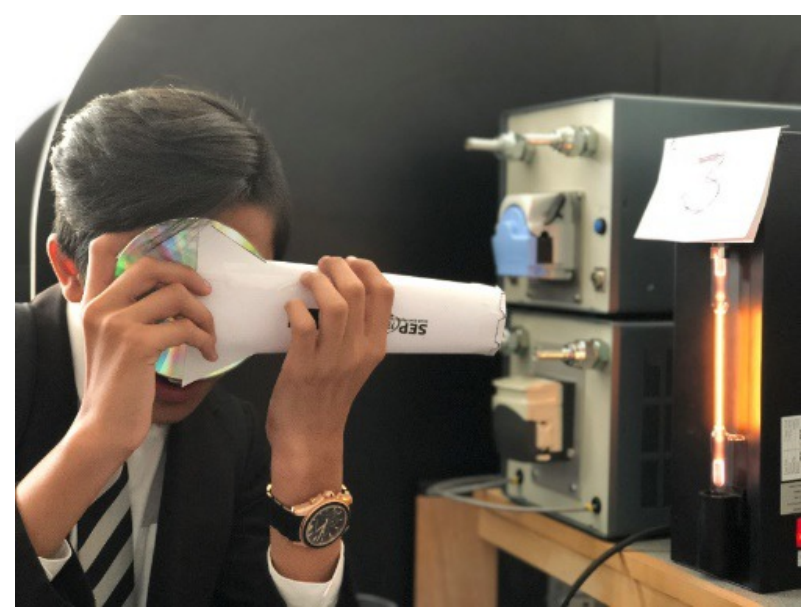

(b)

Figure 3: Pupils taking part in the outreach masterclass. (a) Prentice delivering the "Mobile Ghosts" workshop. (b) A pupil using a spectrometer in the "Guess the Gas" workshop.

The pupils were divided into three separate groups and rotated through the workshops, before reconvening at the end of the day for the Light Express show. For each workshop, two demonstrators were required. To provide pupils with a diverse set of role models, a conscious effort was made to ensure that at least one demonstrator in each class was female. An additional demonstrator was assigned to act in a supervisory role and to handle any practical issues that arose throughout the day, without disrupting the workshops. This demonstrator also delivered the introductory and plenary talks as the workshops were being set up and packed away. To facilitate the movement of the pupils around the campus, 6 undergraduate student ambassadors were supplied by A2S. Figure 3 shows the students taking part in the workshops.
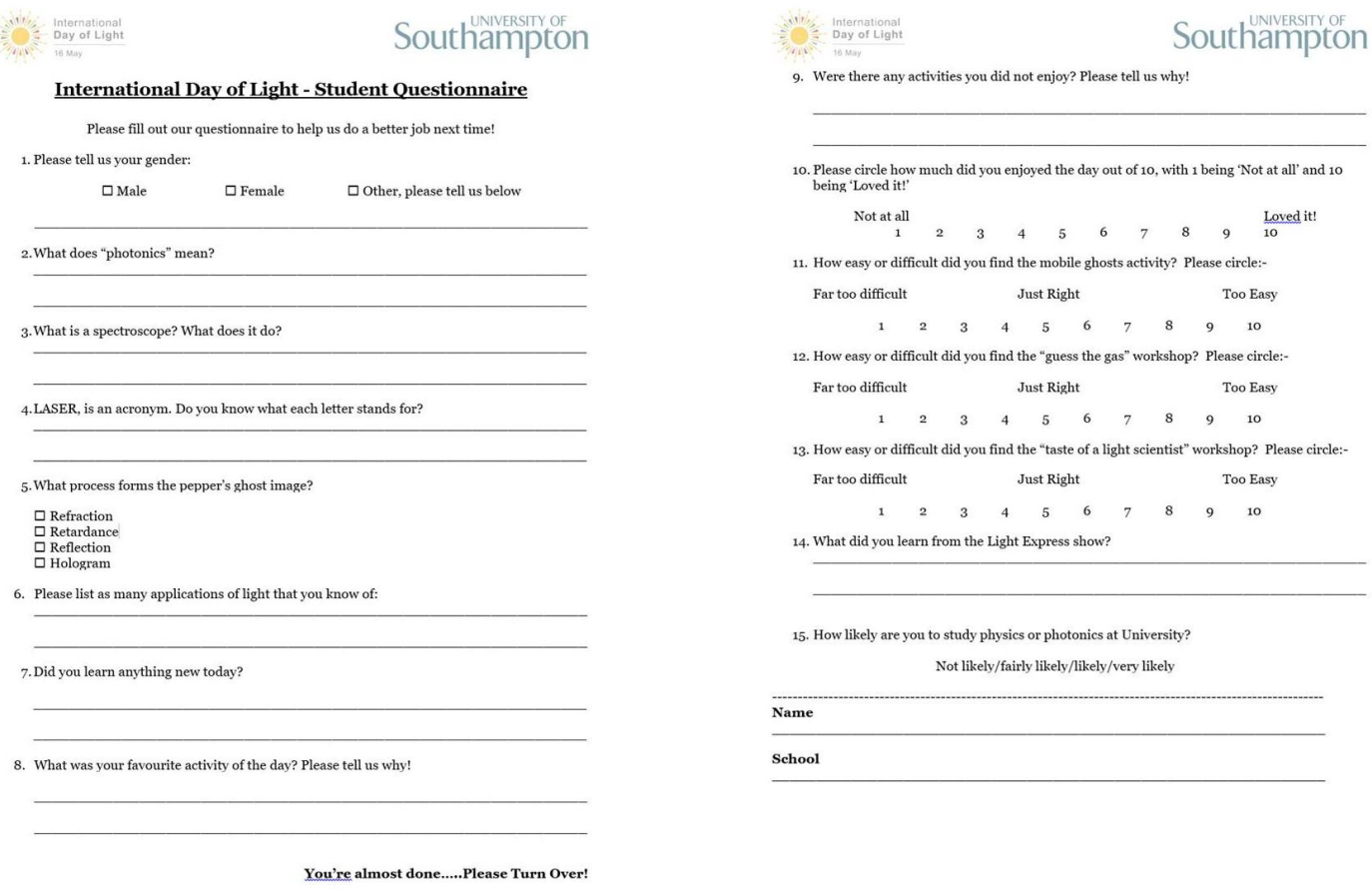

Figure 4: The questionnaire given to the schoolchildren at the end of the outreach masterclass. 
To assess the impact of the event, a questionnaire was given to the pupils at both the beginning and the end of the day. The pre-event questionnaire asked some subject-specific questions to gauge the knowledge of pupils beforehand, to differentiate between what had been learnt and what had already been known. Figure 4 shows the post-event questionnaire. It contained the same knowledge questions as the pre-event form, but also questions regarding the pupils' opinions on the workshops and their delivery. These were important to determine if the workshops were pitched at an appropriate level and whether the students enjoyed them.

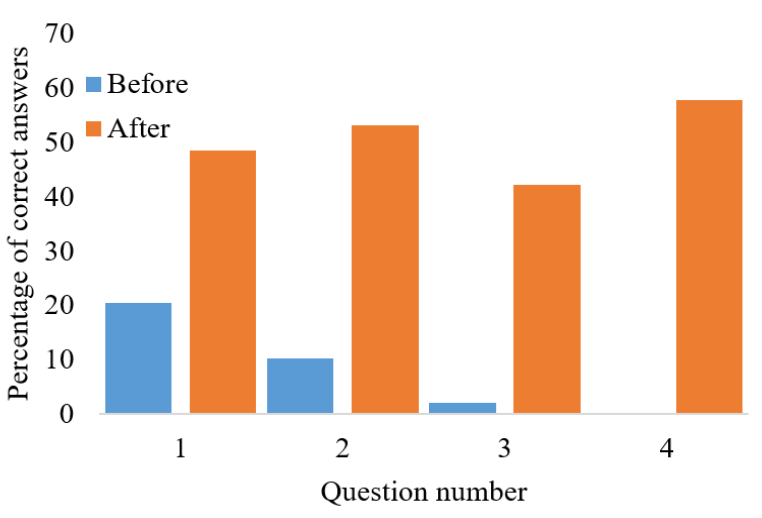

(a)

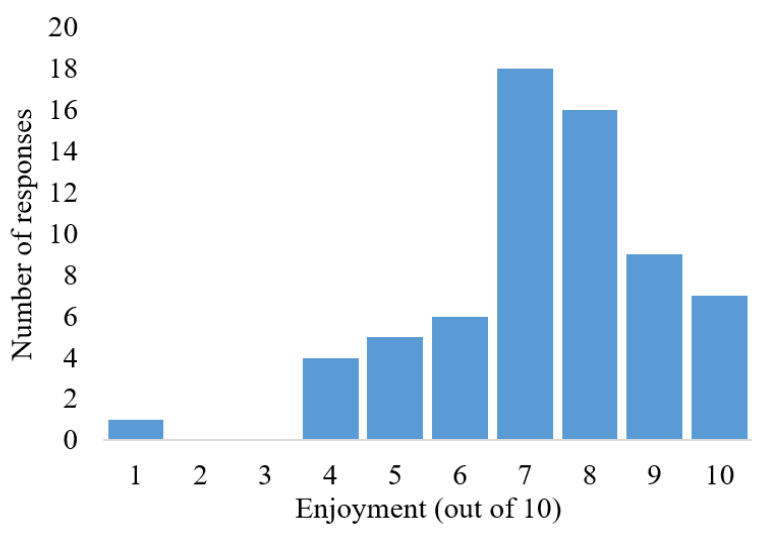

(b)

Figure 5: Responses from the questionnaires. (a) The answers for the subject-specific knowledge questions. (b) The answers on the enjoyment of the outreach masterclass.

Figure 5 shows a summary of the results of question $1-4$ (the subject-specific knowledge questions) and the results of question 10 (the measure of enjoyment). $66 \%$ of the pupils rated the day as 7 out of 10 or above. Furthermore, there was an increase of at least $30 \%$ in correct responses for all knowledge questions. However, the overall percentage of correct answers was above $50 \%$ for only two out of the four questions; this was significantly lower than was expected from experience. The low percentage of correct answers has been attributed to a lack of engagement when completing questionnaires. A lack of engagement during an evaluation has not been previously encountered during the Lightwave Roadshow classes. Upon reflection, two factors may have influenced this: firstly, the evaluation was conducted in a lecture theater with all 75 pupils present. Subsequently, the environment was noisy, disrupting the concentration of the pupils. Secondly, additional evaluation was conducted by A2S and it is suspected that the extensive questioning alienated the children.

\subsection{Art Competition}

Working with the teachers from Cantell School, the art competition was planned over a three-month period to allow sufficient time for the competition to be promoted and for pupils to complete their artwork. This is essential when working with schools, to avoid holidays and exam periods. To avoid clashes with important exams of older pupils but to ensure that the children were older than the target audience of Fun Kids to present the video, Years 8 and $9(12-14$ years old) were selected to be eligible for the competition. The competition was due to be launched in the assemblies for those year groups, followed up by presentations from the teachers in science classes (detailed guidance was supplied to those teachers that were unfamiliar with the project). This also meant that even teachers who were not directly involved with the event could answer questions about it. Example topics were deliberately not given to pupils, so that the artwork would be original and to encourage pupils to research their own topics. It was stressed to the entrants that accurate depiction of the science and a clear description were as important in their entry as the quality of the artwork was.

The launch of the competition during the assemblies and a planned follow-up session in the school's "Girls' Week" were both cancelled due to the school having to rearrange other events in their calendar. The competition was still announced in the classes and posters were displayed around the school, but to increase enthusiasm for it, workshops with the Lightwave Roadshow were organized. Verbal feedback from the teachers at the school reported increased excitement for the project. After-school sessions were planned to provide the pupils opportunity to complete their work or to ask questions from PGR students about light phenomena. However, communication with teachers was disrupted and unfortunately, these sessions could not be organized. In our experience, this is common due to the teachers' busy schedules. 
The lack of continuous follow-up meant that enthusiasm for the competition waned as pupils became preoccupied with other work and the school holidays. Consequently, as the deadline of the competition approached, intensive sessions to produce the artwork were organized with the school. This resulted in a total of 76 entries, all of which were displayed at the public forum. Unfortunately, due to most of the artwork being finished in these sessions, there was a lot of overlap between students over the inspiration of the work and many did not have the description alongside. On judging the winners, the criteria were adjusted slightly to represent the entered work; they were assessed against the accuracy of the depiction of the phenomenon (rather than demonstrating knowledge in the description), alongside the creativity shown and the quality of the artwork. The winning pieces are shown in Figure 6.

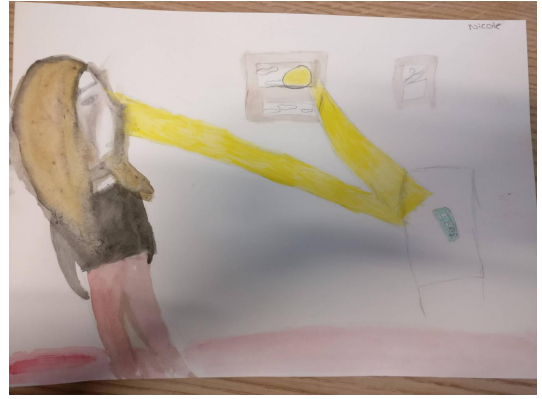

(a)

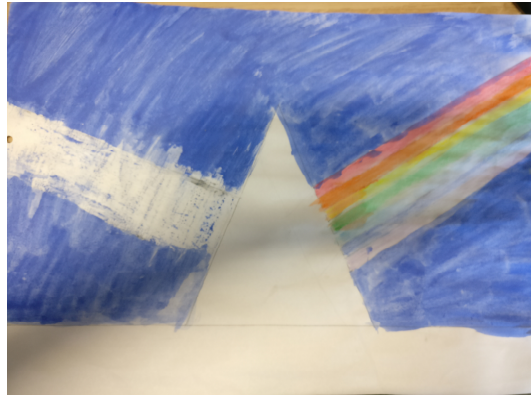

(b)

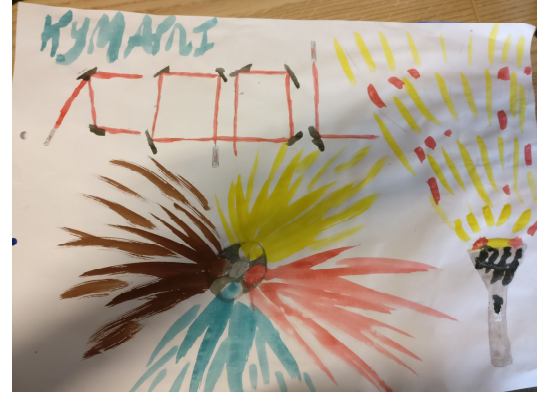

(c)

Figure 6: The three winning pieces from the art competition: (a) shows how human sight works, with light from the Sun reflecting off an object and into the eye; (b) shows the separation of white light into different colors using a prism; and (c) shows mirrors set up in a way so that the laser beam path shows the word "COOL", a mirror ball reflecting different colors and light being emitted from a torch.

\subsection{IDL Video}

The winners of the art competition were notified through the teachers and then invited to take part in the video, one of whom declined. The other two pupils were sent a sheet of the topics that were going to be spoken about in the video. The intention was to get the children to have a filmed discussion with two PGR students around the topics from the sheet that were unfamiliar with. The pupils were asked to prepare questions ahead of time; the logic behind this was that the pupils would ask similar questions to the younger children. The conversational style of the video was to put the pupils at ease at being on camera and that they did not to learn lines or read off a script. However, when starting this discussion, it quickly emerged that a better method was to ask the pupils questions and let them arrive to the answer through discussion and deduction. During this, the pupil state the correct fact or explanation as they gained understanding of the principle. Using this method, the filming became a learning experience for both the pupil and the PGR student, and also provided better footage. Over 3 hours of footage were recorded, before edited down to the approximately 6-minute long final video, shown in Video $1^{15}$.

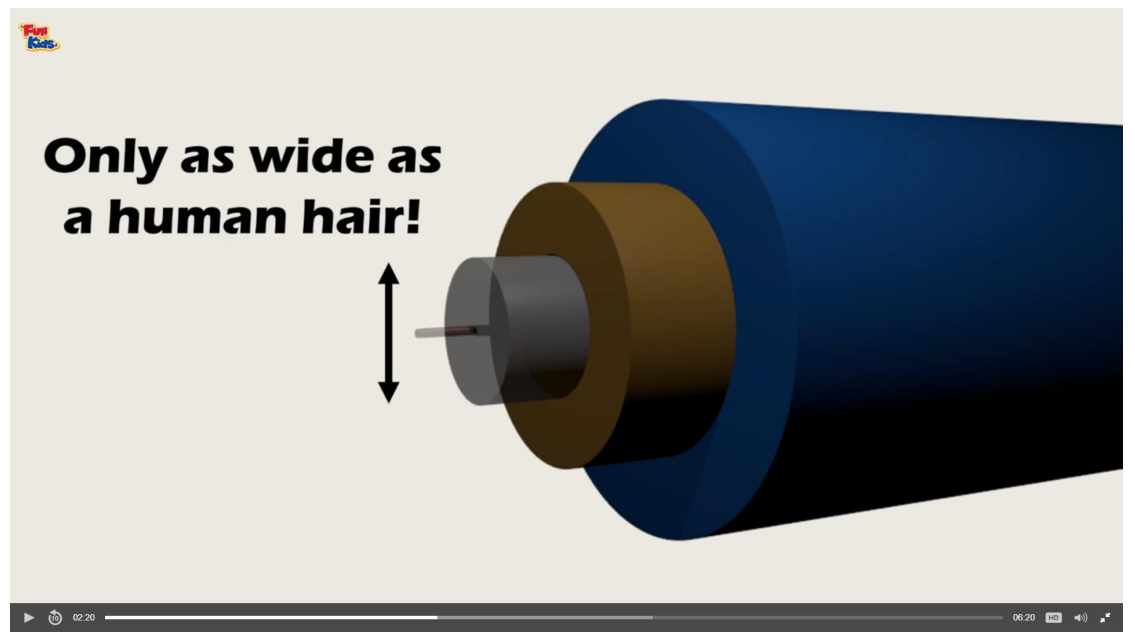

Video 1: A still of the IDL video, hosted on the Fun Kids website. http://www.funkidslive.com/news/1088572/ 
Video 1 was uploaded to the Fun Kids website for the IDL. Unfortunately, unlike like other websites that are commonly used for hosting videos, Fun Kids has no measure of how many views the video has had. This means that there is no direct metric for evaluating the reach of the video.

\section{LESSONS LEARNED}

All of these events were designed in a way such that they do not require any specialist expertise to run. The public forum could be repeated by any other institution but using speakers reflective of its own specialisms. The outreach masterclass drew on the experience of the Lightwave Roadshow and the IYL 2015 when designed, but the workshops could be substituted for those from other outreach programs. The art competition, while a novel event that promotes the STEAM agenda, is easily repeatable in any school with basic art supplies; the accompanying video can be easily replaced with a prize more accessible to groups without the necessary resources. By combining these different activities, the program works for many different areas of society and is effective about communicating the message of the IDL.

However, for this format of events to be effectively repeated by other groups, it is important to evaluate the experiences of the first attempt of the program. Firstly, the significance of developing partnerships is evident throughout these activities, as many of the successes would not have occurred without the collaboration with other groups. Many universities and other groups have pre-existing programs; working with them maximizes resources and can create a bigger impact.

When working with schools, it is important to plan activities both far in advance and to be flexible. The difficulties that arose in both the outreach masterclass and the art competition were due to schools changing their plans at late stages. Without adaptability, this could lead to an ineffective activity. To this end, consistent and frequent contact with the school is essential so that any changes or problems can be addressed as early as possible. Furthermore, the outreach masterclass greatly benefitted from the demonstrator that was unattached to a particular workshop to coordinate the schools and the arrangements of the event in the background; this would be recommended for larger events.

Finally, the smaller audience of the public forum and the low participation in the PGR poster competition were most likely due to advertising them both too close to the event and without enough notice. A full media strategy should be planned out months in advance, with the rest of the planning, to fully take advantage of the available channels.

\section{CONCLUSION}

A format of outreach and public engagement activities that is repeatable by other institutions for future celebrations of the IDL has been presented. Based on this first attempt at this format, some challenges of these events have been identified, such as negative impact of suboptimal media strategies and the difficulties in successful planning with schools. However, we have also provided suggestions to overcome these and have also highlighted effective methods to maximize limited resources and audience engagement. Outreach and public engagement play a large part in increasing engagement with STEM and the diversity of those involved in the field. The recurring nature of the IDL presents a perfect opportunity for the same message to be repeated annually and many groups following the same format worldwide will have a much greater impact than the work based around one institution.

\section{ACKNOWLEDGMENTS}

The authors acknowledge the receipt of a SPIE IDL Micro Grant and funding from the Doctoral College of the UoS to carry out the program of events detailed; the UoS A2S scheme for funding PGR students to run the activities and coaches for the outreach masterclass, for liaising with the schools and providing student ambassadors to help it run smoothly; the Engineering and Physical Sciences Research Council (EPSRC) grant EP/N00762X/1 (National Hub in High Value Photonics Manufacturing) for funding the PGR students to run the Light Express roadshow; Pearl John for running the Light Express roadshow and for her expert advice and support throughout the program; Stephen Fuge and Louise Gillam from Cantell School for their energy and enthusiasm in working with the authors for the art competition; the Media Development team of Digital Learning at the UoS for the loan of the media equipment; Fun Kids radio station for 
hosting the IDL video on their website; the demonstrators of the Lightwave and Light Express roadshows for their contributions in running the outreach masterclass sessions; the OPSoc committee and the student ambassadors for helping with the logistics of the public forum and the outreach masterclass respectively.

Stirling recognizes the support of SPIE, the UoS Doctoral College, the Institute of Physics, the C R Barber Trust, the EPSRC grant EP/N00762X/1 (National Hub in High Value Photonics Manufacturing) and OPSoc to attend Optics Education and Outreach V.

\section{REFERENCES}

[1] United Nations Educational, Scientific and Culture Organization, "Records of the $39^{\text {th }}$ session of the General Conference." 39 C/Res.15 (2017)

[2] UN General Assembly, "International Year of Light and Light-based Technologies, 2015." A/RES/8/221 (2014).

[3] "Access and participation plans", Office for Students, 2018, <https://www.officeforstudents.org.uk/advice-andguidance/promoting-equal-opportunities/access-and-participation-plans/ $>\left(24^{\text {th }} \mathrm{July} 2018\right)$.

[4] "Embedding public engagement", UK Research and Innovation, 2018, <https://www.ukri.org/publicengagement/research-council-partners-and-public-engagement-with-research/embedding-public-engagement/> (24 $4^{\text {th }}$ July 2018).

[5] "About Us," Optics and Photonics Society, 2018, <https://efolio.soton.ac.uk/blog/opsoc/about-us/> (13 ${ }^{\text {th }}$ July 2018).

[6] "Partners," XVI Symposium of Mexican Students and Studies in the UK, 2018, $<$ https://www.symposiummx.com/partners $>\left(23^{\text {rd }}\right.$ July 2018).

[7] Wong, N. H. L., Posner, M. T. and John, P. V., "The Lightwave Programme and Roadshow: An Overview and Update," Proc. SPIE 9793, 9793V, 1-16 (2015).

[8] Posner, M. T., Jantzen, A., van Putten, L., Ravagli, A., Donko, A. L., Soper, N. H. L. and John, P. V., "Cathedral outreach: student-led workshops for school curriculum enhancement in non-traditional environments," ETOP 2017 Proceedings, 1045207 (2017).

[9] Posner, M. T. "Optical integrated circuits for large-scale quantum networks," PhD Thesis, University of Southampton (2017).

[10] Wong, N. H. L., Posner, M. T., Mittal, V. Gray, D. R. and John, P V., "Taking local optics outreach abroad for IYL 2015: administrative and logistical challenges and strategies," Proc. SPIE 9946, 9946-14 (2016).

[11] Posner, M. T., John, P. V., Standen, D., Wheeler, N. V., van Putten, L. D., Soper, N., Parsonage, T., Wong, N. H. L. and Brambilla, G., "Reflecting photonics: Reaching new audiences through new partnerships: IYL 2015 and the Royal Horticultural Society flower show," Proc. SPIE 9946, 9946-2 (2016).

[12] Posner, M. T., John, P. V., Wong, N. H. L., Mittal, V. and Nunez-Velazquez, M. M., "From school classes to UNESCO: IYL-enabled environments for tackling the STEM skills shortage through student-led outreach," Proc. SPIE 9946, 9946-6 (2016).

[13] "Goals", International Day of Light, 2017, <https://www.lightday.org/goals > (13 ${ }^{\text {th }}$ July 2018).

[14] "The Light Express", University of Southampton, 2012, <http://www.lightexpress.soton.ac.uk/> (23 ${ }^{\text {rd }}$ July 2018).

[15] Wright, S., "The 30-second briefing: What is Steam?," TES, 2016, <https://www.tes.com/news/30-secondbriefing-what-steam $>\left(23^{\text {rd }}\right.$ July 2018$)$.

[16] “Case Studies", STEM to STEAM, 2018, <http://stemtosteam.org/case-studies/> (23 ${ }^{\text {rd }}$ July 2018).

[17] “Cantell School", Ofsted, 2017, < https://reports.beta.ofsted.gov.uk/provider/23/116469> (22 $\left.2^{\text {nd }} J u l y ~ 2018\right)$.

[18] Stirling, C., "International Day of Light is on May $16^{\text {th }}$ ! Check out this video about the day!," Fun Kids, 2018, $<$ http://www.funkidslive.com/news/1088572/> $\left(13^{\text {th }}\right.$ July 2018). 